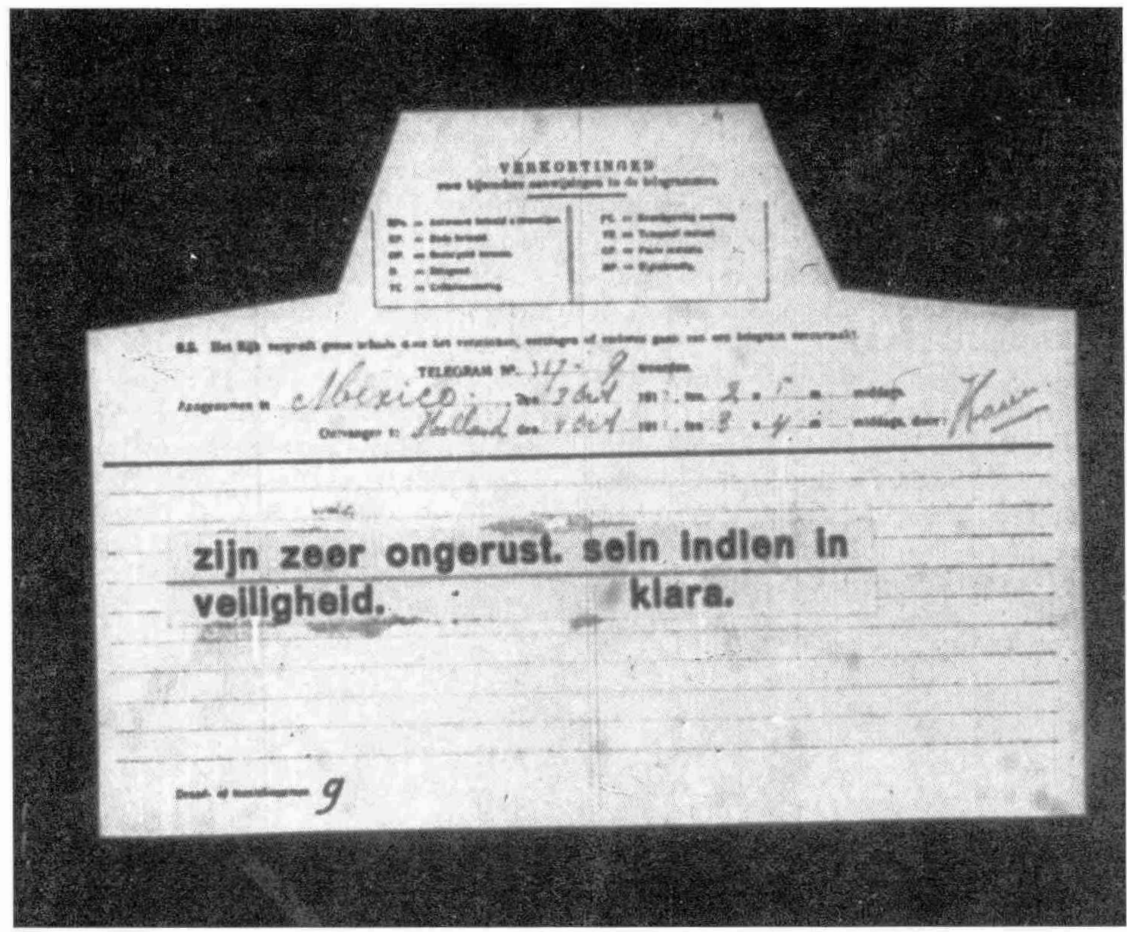




\title{
Redes empresariales y proyectos bancarios en la Mesa Centro-Norte de México (1870-1910)
}

\author{
Moisés Gámez*
}

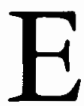
1 sistema financiero estudiado se desenvolvió en un espacio económico que durante las dos últimas décadas del siglo XIX se encontraba en reconfiguración hacia un sistema más consolidado, fortalecido por una red sostenida en relaciones económicas comerciales, agrícolas, mineras e industriales, lo que indica la vinculación entre el crédito y otras actividades en la Mesa Centro-Norte de México. En este sentido, la importancia de elaborar estudios comparativos que confronten diversas experiencias adquiere mayor relevancia, pues contribuyen "a la formulación de enfoques analíticos que permitan una comprensión cada vez más penetrante y matizada de la historia económica mexicana moderna".

* Doctor en Historia Económica por la Universidad Autónoma de Barcelona. Profesor-investigador de El Colegio de San Luis, A. C. Sus temas de investigación son: historia económica, historia empresarial, minería y estudios sobre clase obrera. Entre sus publicaciones destacan: Unidad de clase y estrategias de resistencia. Los trabajadores en San Luis Potosi, 1890-1917, Ponciano Arriaga, San Luis Potosí, 1997; De negro brillante a blanco plateado. La empresa minera mexicana a finales del siglo XIX, El Colegio de San Luis, San Luis Potosí, 2001; coordinador y autor de capítulo en Espacios y procesos mineros. Mineria y fundición en centro y noreste de México durante el porfiriato, Plaza y Valdés/El Colegio de la Frontera Norte, Tijuaja, 2004. Director de Vetas, revista de El Colegio de San Luis, 2000-2002.

${ }^{1}$ Cerutti y Marichal, "Estudio", 2003.
Uno de los puntos de partida para este trabajo es que hubo una proliferación de sociedades nacionales en la Mesa, aunque con limitada expansión frente a la extensión y el predominio que tuvieron las extranjeras. Sin embargo, hubo proyectos nacionales fuertemente capitalizados, en los cuales, si bien no era la totalidad de la inversión, ésta sí era significativa en cuanto a su asociación con otras de diverso origen. Parte de las explicaciones se encuentran en las formas de financiación, proceso en el cual influía la disponibilidad de capitales, los costos de intermediación y las condiciones para la inversión. ${ }^{2}$ Ante este panorama, es necesario aclarar que la inversión nacional fue significativa en determinados momentos durante el periodo, por lo que su análisis adquiere relevancia en el estudio de la economía regional y de los sistemas financieros.

\section{CRÉDito PREBANCARIo}

Respecto a las formas de financiamiento es pertinente analizar el crédito prebancario. Por un lado, se propone que la participación de los comerciantes fue negativa para el desarrollo de empresas de diversa envergadura debido a la dependencia económi-

\footnotetext{
2 Gámez, "Propiedad", 2004.
} 
ca y al alto costo del capital. Por el otro, que el crédito prebancario estimuló las economías regionales a través de la articulación de diversas actividades y agentes económicos. Un ejemplo es que el crédito de comerciantes tuvo tres consecuencias: 1) generalizó el crédito laico; 2) multiplicó el traslado de propiedades a manos burguesas, y 3) estimuló la producción bajo el capital en sectores que articularon el incipiente mercado interior con el internacional. ${ }^{3}$ Estudios plantean que en determinados espacios ocupados por casas comerciales, no padecieron el reemplazo o fueron afectadas de manera crítica por actividades bancarias en la segunda mitad del siglo XIX. ${ }^{4}$ Sostengo que en el caso de la Mesa Centro-Norte coexistieron ambas formas de financiación, y que al final del periodo se mostró una preeminencia de la banca formal con un desarrollo desigual.

Inicialmente, los comerciantes eran quienes contaban con capacidad financiera gracias a la naturaleza de su actividad. De alguna manera sustituían el sistema bancario, $y$ funcionaron como base de las transacciones financieras en la Mesa y fuera de ella. Según testimonios, la situación en San Luis no era muy esperanzadora para los inversionistas, pero sí para los prestamistas:

el dinero escaseaba enormemente en todo el estado, siendo difícil de conseguir el circulante, que era todo metálico difícil de llevar y traer. Nadie prestaba dinero a menos de $24 \%$ anual, pues desde que desaparecieron los bienes de las órdenes religiosas, que eran las que prestaban al $6 \%$ manteniendo a raya a usureros, éstos abusaban entonces por falta de competencia. ${ }^{5}$

${ }^{3}$ Cerutti, Propietarios, 2000, p. 48.

${ }^{4}$ Cerutti, "Expansión", 1993.

${ }^{5}$ Cabrera y Cabrera, San, 1978, p. 102.
El tipo de interés establecido en San Luis Potosí refleja el alto costo de pedir prestado, que inhibía la inversión.

Sumado a la fragmentación de medios de pago, existía la profesión de corredor, el cual se encargaba de representar personas, empresarios y sociedades. Algunos invertían y se mostraban "deseosos de tener algún participio" en determinado negocio. ${ }^{6}$ Esto aseguraba de alguna manera las transacciones, pero es evidente la ausencia de un espacio económico unificado de instituciones financieras modernas y de activos tangibles.

En San Luis Potosí, el conjunto de mecanismos crediticios y de movilización de fondos estaba asentado en redes personales y familiares controladas en buena medida por comerciantes. Como antecedentes de dichas prácticas, a mediados del siglo XIX Pittman y Compañía, "comisionistas y banqueros", hacía transferencias de capitales y bienes de comerciantes a empresarios agrícolas, ganaderos y mineros; el Cajón de Ropa La Palestina de Muriedas y Compañía era un negocio que funcionaba como centro de operaciones comerciales y financieras -la empresa comercial más importante de la plaza hacia la década de 1880-, se vendían artículos de importación de Europa y Estados Unidos; era un punto de reunión de empresarios prestamistas, corredores y "banqueros". Otras casas eran: el almacén de Juan $\mathrm{H}$. Bahnsen y Compañía, las bodegas de importaciones y productos nacionales de José Ma. Ota-

6 "Venta de acciones de la Compañía Minera Las Catitas y Anexas, S. A., por Roberto Ipiña a favor de Teófilo Torres", 19 de febrero de 1904, en Archivo Histórico del Estado de San Luis Potosí (en adelante AHESLP), fondo Registro Público de la Propiedad y del Comercio, Matías Arias, prot. 1904 I, insc. 16. 
hegui y Sucesores, la de Federico Meade y Hermanos, y la de Aresti y Compañía -almacén de efectos del país y extranjeros. Las operaciones de casas comerciales también revelan el vínculo entre las actividades comerciales, industriales y mineras que demandaban desde caballos, mulas, granos y energéticos, hasta maquinaria, herramientas, químicos, manufacturas nacionales y extranjeras, manteniendo fuertes vínculos con el comercio exterior.

Los propietarios y empresarios que intervenían en el mercado financiero a finales del siglo XIX en San Luis Potosí eran Matías Hernández Soberón, Federico Meade, Moisés Perogordo, los hermanos Barrenechea, Ruperto Macías Valadés, Macedonio Gómez, Francisco Grande y José María Grande. El abogado Moisés Perogordo se desempeñaba como intermediario en empresas de distinta naturaleza. Funcionaba como agente financiero para la inversión en tecnología innovadora. Su radio de acción comprendía San Luis Potosí y Zacatecas desde la década de 1880 ; en esa década fue gerente del Banco Mercantil Mexicano. ${ }^{7}$ Sus relaciones sociales y económicas se fortalecieron por el vínculo matrimonial con un miembro de la familia Espinosa y Cuevas. También Anastasio Hernández Soberón y José Encarnación Ipiña eran prestamistas en la década de 1880 , se desempeñában en Matehuala aplicando una tasa de interés de $1 \%$ mensual. Pittman y Compañía hacía préstamos personales en la década de 1884 por cantidades desde 2200 pesos pagaderos a ocho meses con obligaciones prendarias. ${ }^{8}$

${ }^{7}$ Periódico Oficial del Estado de San Luis Potost, 7 de noviembre de 1882 .

8 "Obligación prendaria de varias acciones mineras en el socavón Dolores Trompeta y Anexas por
Créditos de comerciantes y empresarios potosinos financiaron empresas instaladas en Zacatecas y establecieron una amplia relación económica en la Mesa. Los montos llegaban a 180000 pesos. Asimismo, se financiaron proyectos fuera de la Mesa, sobre todo por agentes cuyas relaciones económicas estaban fincadas en el occidente de México, como las de Carlos B. Bringas y Moisés Perogordo, constituyéndose como casos ejemplares en Pozos (Guanajuato), en la capital potosina y en la ciudad de Zacatecas. Un aspecto que favorecía a prestamistas o comisionistas era el acceso a la información sobre la disponibilidad de recursos, que permitía adquirir propiedades o acciones de empresas de otros estados. Por esa información recibían una especie de sueldo y compensaciones de hasta 200 pesos. $^{9}$ Esas prácticas contribuyeron a dinamizar el mercado de acciones, que era contrastante en algunos casos, sobre todo si consideramos el monto de los préstamos otorgados.

Sin embargo, ante el estímulo y la financiación de proyectos empresariales, la

Juan Huerta a favor de Matías Hernández Soberón para garantizarle el pago de 1000 pesos", 28 de marzo de 1883 , Isidro Calvillo, prot. XXIX 1883, insc. 45 ; "Obligaciones prendarias de varias acciones de Dolores Trompeta y Anexas por Juan R. Huerta a favor de Matías y Atanacio Hernández Soberón, José Encarnación Ipiña y Matías Hernández, quedando sin efecto la escritura que con anterioridad les tenía otorgada", 2 de agosto de 1884, Isidro Calvillo, prot. $\mathrm{xxx} 1884$, insc. 138; "Obligación prendaria por Alberto López Hermosa", 2 de agosto de 1884, Isidro Calvillo, prot. xxx 1884, insc. 157, en AHESlP, fondo Registro Público de la Propiedad y del Comercio.

9 "Cesión de $\mathrm{La} \mathrm{Fe}$ y Providencia y convenio de colaboración", 6 de mayo de 1899, en AHESLP, fondo Registro Público de la Propiedad y del Comercio, Adalberto M. Vázquez, prot. 1C 1899, insc. 42. 
expansión de las sociedades se vio limitada por problemás derivados de la capacidad de pago de créditos. Cuando estaba en ciernes el mercado financiero formal, pero con la participación de agentes ligados al crédito como Felipe Muriedas en San Luis Potosí, las compañías enfrentaron problemas de liquidez. De esa forma, las propiedades pasaban a manos de prestämistas. ${ }^{10}$

Antes de la instalación de la banca en Zacatecas, los comisionistas que controlaban el mercado informal eran Antonio Kimball, Rafael Sescosse, Joaquín Améza * ga, Fernando Lejeune, Flores y Compañía, y Gualterio C. Palmer, entre otros. El tipo de interés en la década de 1890 rondaba el $6 \%$ para créditos de 800 a 8000 pesos y se respaldaban con $10 \%$ de las ventas. ${ }^{11}$ Como en la mayoría de los casos estudiados para la Mesa, cuando los préstamos no llegaban a buen término los comisionistas iniciaban un juicio ejecutivo mercantil por incumplimiento de contrato. De esa manera accedían a la cartera accionaria, ${ }^{1.2}$ de tal manera que cualquier capital era susceptible de ser potenciado para posteriormente poner las acciones en el mercado.

${ }^{10}$ Adalberto M. Vázquez, prot. XI 1900 , insc. 37, 12 de marzo de 1900, en AHESLP, fondo Registro Público de la Propiedad y del Comercio.

11 "Cesión de derechos de crédito hipotecario contra José Félix Cabrera y Antonio Nepomuceno Félix", 13 de octubre de 1899, Rafael Ceniceros Villarreal, prot. 25, insc. 190; "Ratificación de contrato entre Gualterio C. Palmer y Benjamín Clark”, 8 de septiembre de 1905, Rafael Ceniceros Villarreal, prot. 36, insc. 138, en Archivo Histórico del Estado de Zacatecas (en adelante AHEZ), fondo Notarios.

12 "Adjudicación otorgada por el juez $1^{\circ}$ de lo civil de esta capiral", 21 de noviembre de 1905, en AHESLP, fondo Registro Público de la Propiedad y del Comercio, Jesús Meléndez, prot. 1905 I, insc. 28.
En el caso de Guanajuato la función crediticia durante el porfiriato estuvo en manos de Cipriano y Compañía, Gonzalo y Atanasio Rocha, Ignacio Ibargüengoitia, Stallforth y Alcázar, Eduardo J. Cumming, Dwight Furness y Compañia, y Enrique Langenscheidt, entre otros, con tipos de interés de 6 a $15 \%$ anual. En la década de 1890 el interés predominante para montos de hasta poco más de 13000 pesos se fijaba en $10 \%$ anual. Es decir, eran créditos de pequeña envergadura, con la hipoteca de minas, barras o acciones de haciendas agrícolas, propiedades rústicas y urbanas, entre otras. ${ }^{13}$ La sociedad Cipriano y Compañía realizó transacciones crediticias en Guanajuato y en Jalisco durante ese periodo. Se desarrolló una dinámica de transacciones entre comisionistas, empresarios y empresas, entre las que destaca la Negociación Stallforth y Alcázar.

Según las fuentes consultadas, el tipo de interés tuvo un descenso en Guanajuato al final de esa década; de igual forma, el monto de las préstamos creció. En este señitido, al disminuir el tipo de interés, existieron mejores oportunidades para invertir. Esta tendencia de "bajos" tipos de interés respecto a la década de 1890 se

13 "Préstamo a la Sociedad Cumming y Jiménez", 10 de julio de 1890 , Luis G. López, prot. $18902^{\circ}$ señ, insc. 1; "Préstamo con hiporeca de 500 pesos a Jüan N. Contreras", 19 de julio de 1892, Luis G. López, prot. $1318922^{\circ}$ sem, insc. 4; "Préstano e hipoteca de bienes inmuebles particulares y de $1 / 2$ acción de la Negociación Minera de Pozos", 9 de enero de 1892, Herculano M. Hernández, prot. 1892 1er. sem, insc. 2; "Acuerdo de reconocimientos de deuda y traspaso de derechos entre Mariano Amozurrutia y $\mathrm{Ci}$ priano Rodríguez y Compañía”, 24 de agosto de 1899, Luis G. López, prot. $2518992^{\circ}$ sem, insc. 11, en Archivo General del Estado de Guanajuato (en adelante AGEG), fondo Notarios. 
modificó a mediados de la de 1900 . La explicación tiene una estrecha relación con la aparición de la banca formal en Guanajuato y el paso del patrón bimetálico en México, pues a partir de 1905 se adoptó el patrón oro. Las transacciones crediticias localizadas en los protocolos sugieren que aunque los montos se incrementaron, el tipo de interés se tasó hasta en $18 \%$ anual para cantidades de alrededor de 40000 pesos. En este sentido, es importante mencionar que los balances del Banco de Guanajuato no registraron préstamos hipotecarios entre 1901 y 1903 , sino hasta 1904, con un tipo de interés de $9.5 \%$ anual y de entre 10 y $11 \%$ al tipo ordinario; ${ }^{14}$ precisamente en ese año se notó una baja en los tipos impuestos por las casas comerciales, que prestaban a $8 \%$ anual para un préstamo de 8000 pesos a diez años, por ejemplo. Es dë resaltar que durante esos años se afianzó una relación entre los agentes crediticios particulares y la banca formal, lo que explica la participación directa de dichos agèntes en la conformación o establecimiento de las instituciones bancarias en México.

Para concluir con el apartado, propongo que la actividad financiera a finales del siglo XIX estuvo sustentada por particulares en mayor medida que por instituciones bancarias, es decir, predon̂́inó el crédito informal. El nacimiento de los bancos de emisión e hipotecarios en la Mesa se presentó de forma distinta, como sucedió en Guanajuato y Zacatecas por mencionar un ejemplo, a causa de que las actividades del crédito estaban cimentadas en la oferta privada. Es interesante mencionar que algunos estudiosos proponeñ la existencia de un sistema financiero de monopolio

${ }^{14}$ Memoria, 1904-1906, pp. 547-576. plural, ${ }^{15}$ es decir, un sistema mixto, de coexistencia de dos tipos de empresas crediticias: las del tipo viejo -casas propiedad de banqueros particulares- y las nuevas instituciones bancarias. Aspectos que en seguida muestro para confrontar las hipótesis del apartado anterior.

\section{LAS ORGANIZACIONES BANCARIAS}

Uno de los atractivos para el análisis del sistema financiero es estudiar la posibilidad y efectividad para poner en movimiento recursos dirigidos al desarrollo económico. También es importante para calcular la capacidad de una determinada economía en el estímulo y conformación de un mercado financiero acorde a sus necesidades. ${ }^{16}$ En este apartado abordo la forma en que las instituciones financieras nacieron y evolucionaron en la última década del siglo XIX y las primeras del XX, con especial atención en la conformación de entramados empresariales que posibilitaron en diversa medida la movilización de capitales, y un dinamismo en distintos sectores económicos.

Supongo como premisa que las instituciones financiaron proyectos de mediana envergadura a mediano plazo, con base en vínculos sociales y económicos de los agentes involucrados en los sistemas crediticios, lo que tuvo impactos positivos en la Mesa Centro-Norte. Frente a las cambiantes condiciones en que se desarrolló el sistema bancario mexicano, los estados que forman la Mesa fueron pioneros en el establecimiento de la banca en el ámbito nacional, que proporciona indicios de una

\footnotetext{
${ }^{15}$ Ludlow, "Primera", 1993, p. 359.

${ }^{16}$ Riguzzi, "Pobres”, 1999, pp. 365-366.
} 
relación con las actividades económicas preponderantes en dicho espacio, como la minera.

Cabe mencionar que prácticamente no existían instituciones bancarias en México, solamente existían cuatro pequeños bancos locales en el estado de Chihuahua y el Banco de Londres y México, filial del London Bank of Mexico and South America Ltd., que también operaba en otros países latinoamericanos. ${ }^{17}$ Hacia finales de la década de $1880^{\circ}$ se estableció en San Luis Potosí una sucursal del Banco de Londres y México, representada por Santiago Wastall. ${ }^{18}$ En la década de 1880 se fundaron instituciones como el Banco Nacional Mexicano y el Banco Mercantil Mexicano -fundado el 27 de marzo de 1882. Formaron parte del consejo de administración y accionistas: Porfirio Díaz, José María Roa Bárcena, Indalecio Sánchez Gavito, Antonio Escandón, Nicolás de Teresa, entre otros. Ambos fusionados formaron el Banco Nacional de México en 1884. En esa década prácticamente sucedió el nacimiento del circulante fiduciario y la expansión del crédito, periodo en que el monto de los billetes se incrementó $108 \%$, es decir, de 9600000 a 20000000 de pesos.

\section{El Banco de San Luis Potosí}

Es notable que comerciantes, propietarios, empresarios -en diversas actividades económicas- y comisionistas en San Luis Potosí formaron parte del proyecto bancario potosino. Su desempeño en actividades de financiación desarrolladas durante el siglo

${ }^{17}$ Bátiz, "Trayectoria", 1986.

${ }^{18}$ Montejano y Palacios, Cien, 1997, p. 29.
XIX fue el precedente y sentaron las bases para definir su participación en el establecimiento de las instituciones financieras en la Mesa Centro-Norte, ya que participaron activamente en la fundación de los bancos y en los préstamos otorgados no sólo en San Luis Potosí, sino en Guanajuato, Zacatecas y Aguascalientes.

Eduardo C. Pittman, quien había sido comisionista, estuvo al frente del consejo de administración de la sucursal del Banco Mercantil Mexicano, autorizada en octubre de $1882,{ }^{19}$ junto con Matías Hernández Soberón, Felipe Muriedas, José Encarnación Ipiña y Santiago Wastall. ${ }^{20}$ Pittman continuó dirigiendo la sucursal en San Luis después de la fusión que dio origen al Banco Nàcional de México. Los miembros del consejo permanecieron durante esos años, con inversiones en diversas empresas de la Mesa Centro, integrando juntas de administración o directivas. ${ }^{21}$

En 1884 se emitió el Código de Comercio que estableció los preceptos referentes a la función bancaria y para el establecimiento de cualquier clase de banco en el país. ${ }^{22}$ Esa situación obstaculizó la extensión de la banca en México durante

${ }^{19}$ Firma de contrato entre el estado y Ramón C. Othón e Ignacio Muriel, representantes del Banco Mercantil Mexicano para el establecimiento de una o más sucursales en la ciudad, Periódico Oficial del Estado de San Luis Potosí, 24 de octubre de 1882.

${ }^{20}$ Periódico Oficial del Estado de San l.ais Potosi, 27 de noviembre de 1882 .

21 "Prenda constituida por la señora Elisa Pohls y su esposo Enrique Schroeder a favor de la sucursal del Banco Nacional de México", 21 de diciembre de 1887 , en AHEsLP, fondo Registro Público de la Propiedad y del Comercio, Antonio de Padua Nieto, prot. XXV 1887, insc. 271.

${ }^{22}$ Código, 1884. 
la mitad de la década de 1880 , por lo que las posibilidades de financiamiento se vieron limitadas. En 1888 se facultó al presidente de la república para contratar la instalación de entidades bancarias que fuesen convenientes. En 1896 se cancelaron los contratos otorgados en 1889 a diversos bancos agrícolas e industriales de la ciudad de México, Yucatán, Jalisco, San Luis Potosí, Guanajuato, Zacatecas y Coahuila, y a las instituciones de emisión autorizadas en 1890 en los estados de Sonora, San Luis Potosí, Coahuila y Estado de México. Las últimas fueron "refundadas" meses más tarde bajo los términos de la nueva ley, como sucedió con los bancos de Zacatecas y San Luis Potosí.

El Banco Agrícola Industrial y Minero de San Luis Potosí fue un proyecto de 1889 que aglutinó a empresarios, comerciantes y comisionistas de diversos lugares. Los fundadores y accionistas no efectuaron el depósito de 30000 pesos en bonos de la Deuda Consolidada en los cuatro meses señalados en el contrato, por lo que la validez de la misma se determinó caduca en septiembre de $1897 .{ }^{23}$ Como en otros casos sucedidos en México y en la Mesa -como Zacatecas-, el establecimiento de la banca dependió en gran medida de la capacidad de los empresarios nacionales, de la complejidad en la asociación con extranjeros y del marco institucional que agilizara su desarrollo.

Los mecanismos de financiación favorecían valores de privilegio, en donde figuras políticas recibían financiamiento y plazos preferenciales, como los cedidos al gobernador Carlos Diez Gutiérrez, a Pedro Diez Gutiérrez, a Manuel Rascón y a Pe-

${ }^{23}$ Diario Oficial de la Federación, 16 de marzo de 1897. dro Barrenechea, entre otros. Los créditos otorgados por el Banco Nacional de México también eran de pequeña envergadura, algunos no llegaban a los 1000 pesos. Fueron destinados a empresarios modestos, que posteriormente tuvieron problemas de administración y solvencia para cumplir los contratos contraídos, de tal forma que perdieron las propiedades hipotecadas. ${ }^{24}$

Fue hasta 1897 cuando se otorgaron concesiones para fundar once bancos al emitirse la Ley General de Instituciones de Crédito. ${ }^{25}$ La concesión para establecer el Banco de San Luis Potosí fue otorgada el 15 de junio de 1897 a Gerardo y Eduardo Meade, Matías Hernández Soberón, las sociedades Juan $\mathrm{H}$. Bahnsen y Compañía, Hugo Scherer y Compañía, Rivero y Liaño, Aresti y Compañía, Donato de Chapeauroge y al guanajuatense Ramón Alcázar. ${ }^{26}$ Su capital inicial fue de 500000 pesos, y aumentó posteriormente a 1100000 pesos, con accionistas de Zacatecas como Margarito Gallegos y Elena Aguilera de Dochelar; de Guanajuato como Eusebio González; de Coahuila y de la ciudad de México, entre otros. ${ }^{27}$ El Banco enfrentó dificultades debido a la obligatoriedad sobre la concentración de metálico del capital exhibido en vísperas de su apertura, que impidió la inversión en tan-

24 "Cesión de 4 barras de la mina La Merced", 29 de octubre de 1894, en AGEG, fondo Notarios, Feliciano López, prot. $18942^{\circ} \mathrm{sem}$, insc. 11.

${ }^{25}$ Ley, 1897.

${ }^{26}$ Diario Oficial de la Federación, 15 de junio de 1897.

${ }^{27}$ Decreto 2, 5 de octubre de 1897. Concesión otorgada el 1.5 de junio de 1897, en AHESLP, fondo Secretaría General de Gobierno, colección de Leyes y Decretos. 
to reuniera clientela. Se aplazó la posibilidad de hacer transacciones con su propio capital, pero obtuvo permiso para otorgar créditos hipotecarios en diciembre de $1897,{ }^{28}$ aunque con montos pequeños. ${ }^{29}$ Abrió una sucursal en León cuyo presidente fue Ramón Alcázar, y una en Celaya, en febrero de 1899, bajo la presidencia de Agustín González.

La evolución anual de los consejos de administración muestra el dominio de Matías Hernández Soberón, Eduardo Meade, Tomás Olavaria, Guillermo R. Peterson, Vicente Irízar y Mariano Hernández Ceballos. Enrique Baz -interventor del banco-señaló que los miembros del consejo de administración, además de ser

los principales capitalistas de esta ciudad y de tener establecimientos mercantiles de alto crédito, son distinguidos hombres de finanzas que, por su inteligencia, práctica y experiencia en los negocios, norman siempre las bases de sus operaciones,

quienes garantizaban las transacciones del banco "con la mayor probabilidad de éxito". ${ }^{30}$ De los anteriores, sobresale Matías por sus inversiones en el Banco Mercantil Mexicano en la década de 1880 , en el Banco de San Luis y en el Banco de Guanajuato. La banca potosina respaldó proyectos de pequeña y mediana envergadura. Por ejemplo, Edward L. Doheny obtuvo un préstamo de 50000 pesos del Banco de San Luis, cuando Gerardo Meade era vocal del consejo de administración.

${ }^{28}$ Banco San Luis Potosí, 1901, pp. 11-13.

${ }^{29}$ Memoria, 1900-1902, pp. 464-466.

${ }^{30}$ Ibid., p. 441.

\section{El Banco de Zacatecas}

La banca formal para los zacatecanos fue otra opción empresarial dentro de la diversificación económica, estrategia con la cual establecieron nexos económicos con agentes de la ciudad de México y de otras partes del país. Un grupo de Zacatecas participó en la creación del Banco Mercantil Mexicano con la aportación de 3775700 pesos, es decir, $3.98 \%$ del valor total de las acciones del Banco, estimadas en 72000000 de pesos. ${ }^{31}$ Invirtieron Julián Ibargüengoitia, Juana Bodmer de Alberdi, Kimball y Alberdi, Ramón C. Ortiz, Genaro de la Fuente y Viadero y Compañía, entre otros. La estrategia de expansión del Banco Mercantil Mexicano condujo a establecer una sucursal en la ciudad de Zacatecas en 1882. El Congreso estatal durante el gobierno de Jesús Aréchiga autorizó el establecimiento de dicha sucursal por un plazo de 25 años; sus representantes fueron Julián Ibargüengoitia, Ramón C. Ortiz y Antonio Gómez Castellanos. ${ }^{32}$ Matamala plantea la duda sobre la fecha real de apertura, porque el 3 de febrero de 1883 el gobernador Aréchiga concedió una prórroga por seis meses para abrir la sucursal. Sin embargo, las fuentes consultadas sugieren la apertura, aunque con una vida efímera. De igual forma desconoce sobre la financiación a empresas, por lo se supone un proyecto más en la política de promoción y fomento. En el mismo año el Banco Mercantil Mexicano y el Nacional Mexicano formaron comisiones para plantear la fusión y crear el Banco Nacional de México.

\footnotetext{
${ }^{31}$ Ludlow, "Construcción", 1986, pp. 338-345.

${ }^{32}$ Matamala, "Casa", 1997.
} 
El 3 de marzo de 1891 se otorgó la concesión para el Banco de Zacatecas, con facultades para realizar operaciones de emisión, depósito, descuento y circulación. ${ }^{33}$ El capital suscrito fue de 600000 pesos, divididos en 6000 acciones de 100 pesos cada una. Genaro García -a la postre gobernador del estado- fungió como representante para negociar la concesión ante el gobierno federal. Entre los socios fundadores figuran Rafael Villalpando, Genaro García, Antonio García, Jesús I. García, Luis Macías, Ángela del Hoyo Escobedo, Cayetano Arteaga, Francisco del Hoyo, Benjamín Gómez, Juan A. Petit, Mariano Ibargüengoitia, Juan Bodmer, Agustín Álvarez, Enrique Wüst, Fernando Ponce, Jaime G. Word, Cayetano Arteaga y Leopoldo Viadero, miembro de la familia Viadero, empresarios de San Luis Potosí que poseían Viadero y Compañía, entre otros. La mayoría de las acciones estuvieron en manos de Rafael Villalpando, Jesús Escobedo Nava, y de los integrantes de las familias García y Del Hoyo.

Se otorgaron créditos para Zacatecas, la ciudad de México y Chihuahua, entre otros. De igual forma, los bancos localizados fuera de la Mesa Centro-Norte extendieron sus actividades crediticias. En la década de 1890 el Banco de Durango otorgó créditos a empresarios de Zacatecas, como Joaquín Amézaga, para modernizar infraestructura. ${ }^{34}$

La evolución del Banco durante 1897 fue "perfectamente regular; y afortunada-

${ }^{33}$ Banco, 1891.

34 "Hipoteca de la mina San Antonio del Consejero y la hacienda de beneficio Los Álamos, en Chalchihuites", 15 de febrero de 1892, en AHEZ, fondo Notarios, Román Pérez, prot. 1907, insc. 2. mente las pérdidas sufridas [...] han sido de escasa importancia". ${ }^{35}$ A partir del establecimiento de la ley de 1897 sobre Instituciones de Crédito, se hicieron gestiones ante la Secretaría de Hacienda que dieron como resultado la reforma del contrato de concesión y su formalización en noviembre. El Banco también instaló una sucursal en Aguascalientes y una agencia en Lagos.

A finales del siglo XIX se aumentó el capital. En 1900 renunció Genaro García, presidente del consejo, debido a su elección como gobernador del estado; dicho personaje había presidido la institución desde su fundación. Fue sustituido por Antonio G. García, miembro de la misma familia. Por otro lado, hubo algunos desequilibrios por la crisis monetaria que vivía el país. ${ }^{36}$ No obstante, las previsiones efectuadas por el banco estimaban poca afectación.

El establecimiento del Banco de Zacatecas posibilitó una breve transformación en el mercado financiero, pero las insistentes fluctuaciones cambiarias y el inicio de un proceso inflacionario desde 1902 ocasionaron que el banco tuviera un comportamiento errático en sus utilidades a partir de los años siguiente. Después de un leve repunte en 1905, padeció los efectos de la crisis, de manera que entre 1906 y 1908 experimentó un decremento en sus utilidades. A partir del último año el Banco tuvo que enfrentarse a un mayor número de disposiciones y vigilancia por parte de las autoridades hacendarias de la federación, justo en la transición de las instituciones bancarias hacia la formación de una autoridad emisora central y el con-

${ }^{35}$ Banco, 1898, p. 12.

${ }^{36}$ Banco de Zatatecas, 1901, p. 12. 
trol más efectivo de los instrumentos de política monetaria. ${ }^{37}$

\section{El Banco de Guanajuato}

Las actividades del Banco Nacional de México contemplaban el descuento de letras de casas comerciales que representaban la clientela importante del Banco, la apertura de cuentas corrientes, la recepción de depósitos, operaciones de giro, cambio de moneda extranjera, entre otras. Las sucursales fueron expandiendo paulatinamente su clientela, otorgando créditos a agricultores, comerciantes, fabricantes, propietarios urbanos, entre otros. Las operaciones generalmente eran a corto plazo, y posteriormente a mediano y largo plazo en fábricas, empresas metalúrgicas y compañías ferroviarias, de tal forma que cada vez tuvo un papel de banco de inversiones. ${ }^{38}$

A partir de la ley de instituciones de 1897 se generó una expansión de bancos de emisión. Dicha extensión incluyó la constitución del Banco de Guanajuato S. A. ${ }^{39}$ el 25 de abril de 1900 , institución que reunía empresarios de Guanajuato, San Luis Potosí, la ciudad de México y otros estados, entre los que destacan Ramón Alcázar, Sucesores de Eusebio González, el conocido banquero, minero y propietario Enrique C. Creel -residente en Chihuahua, a título personal y apoderado de la Compañía Banquera Anglo Mexicana, controlada por Antonio V. Hernández y Juan F. Brittingham-, los industriales,

${ }^{37}$ Kuntz y Jáuregui, "Pasado”, 1995, p. 159.

${ }^{38}$ Marichal, "Nacimiento", 1986, pp. 263-264.

39 "Constitución del Banco de Guanajuato", 15 de agosto de 1900, en AGEG, fondo Notarios, Luis G. López, prot. $2819002^{\circ}$ sem, insc. 11. mineros y empresarios agrícolas Eduardo Meade -banquero apoderado de Banco de San Luis Potosí-, Gerardo Meade, Matías Hernández Soberón, Mariano Hernández Ceballos y Juan H. Bahnsen y Compañía, entre otros. Interesante de mencionar es la gama de intereses en diversas actividades económicas de la familia Meade en San Luis Potosí y Guanajuato, quienes poseían propiedades y participación accionaria en empresas en ambos estados. La presencia de estos agentes fue posibilitada por la sólida relación de los inversores de San Luis Potosí, quienes desde 1880 estuvieron interesados en la creación del proyecto bancario guanajuatense, con un capital de 200000 pesos. ${ }^{40}$ No obstante, fue hasta 1900 cuando se concretó el proyecto, obviamente con empresarios asociados a la banca de ambos estados, que manifestó el entramado extendido en la Mesa Centro-Norte mexicana.

El Banco instaló una agencia en Irapuato y otra en Zamora. Tuvo un capital inicial de 500000 pesos, dividido en 5000 acciones de 100 pesos cada una. Amplió periódicamente su capital hasta los 3000000 de pesos con la finalidad de expandir el sistema bancario y establecer sucursales en los estados de Jalisco y Michoacán. De esa manera, en $1903,{ }^{41}$

40 "Proyecto de Estatutos del Banco de Guanajuato", en AHESLP, fondo Secretaría General de Gobierno, leg. 1880, enero, 7.

41 "El consejo de administración del Banco de Guanajuato, S. A., declara que según acuerdo de asamblea general ordinaria se reforman algunas cláusulas de la escritura social de dicho banco y se aumenta su capital social", 18 de abril de 1903, en AGEG, fondo Notarios, Luis G. López, prot. 341903 ler. sem, insc. 26. 
$1904^{42}$ y $1905^{43}$ reformó estatutos y planteó cambios en la composición del capital y sus accionistas, enfrentando el riesgo evidente de la inflación y de cumplimiento de las reglas básicas de su funcionamiento. Operaba como depositario de capital procedente de proyectos empresariales convenidos con el Estado, principalmente planes de reconversión tecnológica y estrategias de financiamiento. ${ }^{44}$ En este sentido, resalta la relación del Estado, las finanzas y los empresarios. De forma semejante que en San Luis Potosí y Zacatecas, las relaciones personales formaron parte importante de los mecanismos financieros. Sobresalen las operaciones de Dwight Furness, Ignacio Ibarguiengoitia, Bahnsen y Compañía, Manuel Ajuria y George W. Mc Elhiney, entre otros. ${ }^{45}$

42 "Reformas y adiciones a la escritura social del Banco de Guanajuato, S. A.", 26 de diciembre de 1904, en AGEG, fondo Notarios, Luis G. López, prot. $3719042^{\circ}$ sem, insc. 47.

43 "Aumento de capital del Banco de Guanajuato, S. A.", 12 de diciembre de 1905 , en AGEG, fondo Notarios, Luis G. López, prot. $3919052^{\circ} \mathrm{sem}$, insc. 56.

44 "Contrato de concesión para explotar el río de Guanajuato", 31 de mayo de 1902; Joaquín Obregón González, gobernador de Guanajuato en 1902, en AGEG, fondo Notarios, Herculano M. Hernández, prot. 1902 ler. sem, insc. 61.

45 "Préstamo a Dwight Furness por el Banco de Guanajuato, S. A.", 7 de diciembre de 1904, Luis G. López, prot. $3719042^{\circ}$ sem, insc. 39; "Poder especial a Adolfo Margain por el Banco de Guanajuato", 9 de noviembre de 1903, Luis G. López, prot. 351903 $2^{\mathrm{n}} \mathrm{sem}$, insc. 27; "Declaración y obligación con hipoteca de George W. Mc Elhiney al Banco de Guanajuato, S. A.", 1904, Herculano M. Hernández, prot. 36 $19042^{\circ} \mathrm{sem}$, insc. 32, en AGEG, fondo Notarios.

\section{TRAYECTORIA COMPARATIVA}

DE LA BANCA EN LA MESA

De acuerdo con la gráfica 1 , es evidente que desde el año de 1900 hubo un notable aumento del capital social bancario en la Mesa, situación que tuvo su mayor auge hacia 1905. Posteriormente se observa una curva plana. Los incrementos generales se debieron primordialmente al aumento de capital del Banco de Guanajuato, que tuvo un repunte y un despliegue mayor que la banca de los demás estados.

Por otro lado, la tendencia sobre los préstamos hipotecarios entre 1900 y 1911 detenta un notable incremento a partir de 1905 (gráfica 2), justo cuando sucedió el cambio del sistema monetario al patrón oro en México. El momento de mayor auge sucedió entre 1907 y 1909 , para caer levemente hasta 1910 , con una ligera recuperación al final del periodo de estuclio. Hay que recordar que la regulación bancaria por parte del gobierno principió a partir de 1908 con la reforma a las instituciones de crédito.

Es visible que el banco con mayor actividad crediticia fue el de Guanajuato, emplazado en un ámbito donde la minería fue una de las actividades económicas fundamentales. Los préstamos fueron destinados a la implantación de nuevos proyectos y a la renovación tecnológica. Con creces superó las posibilidades de la banca de San Luis Potosí y Zacatecas. Sin embargo, hay que recordar que en dicha entidad se desplegó una red empresarial de mayor envergadura que articuló de manera más sólida la Mesa a través de la inversión de empresarios de San Luis Potosí, y en otras partes, como fue el caso de Enrique C. Creel.

Durante el año de 1911 las transacciones realizadas por el Banco de Guanajuato 
Gráfica 1. Capital social de la banca en la Mesa Centro-Norte de México, 1900-1911

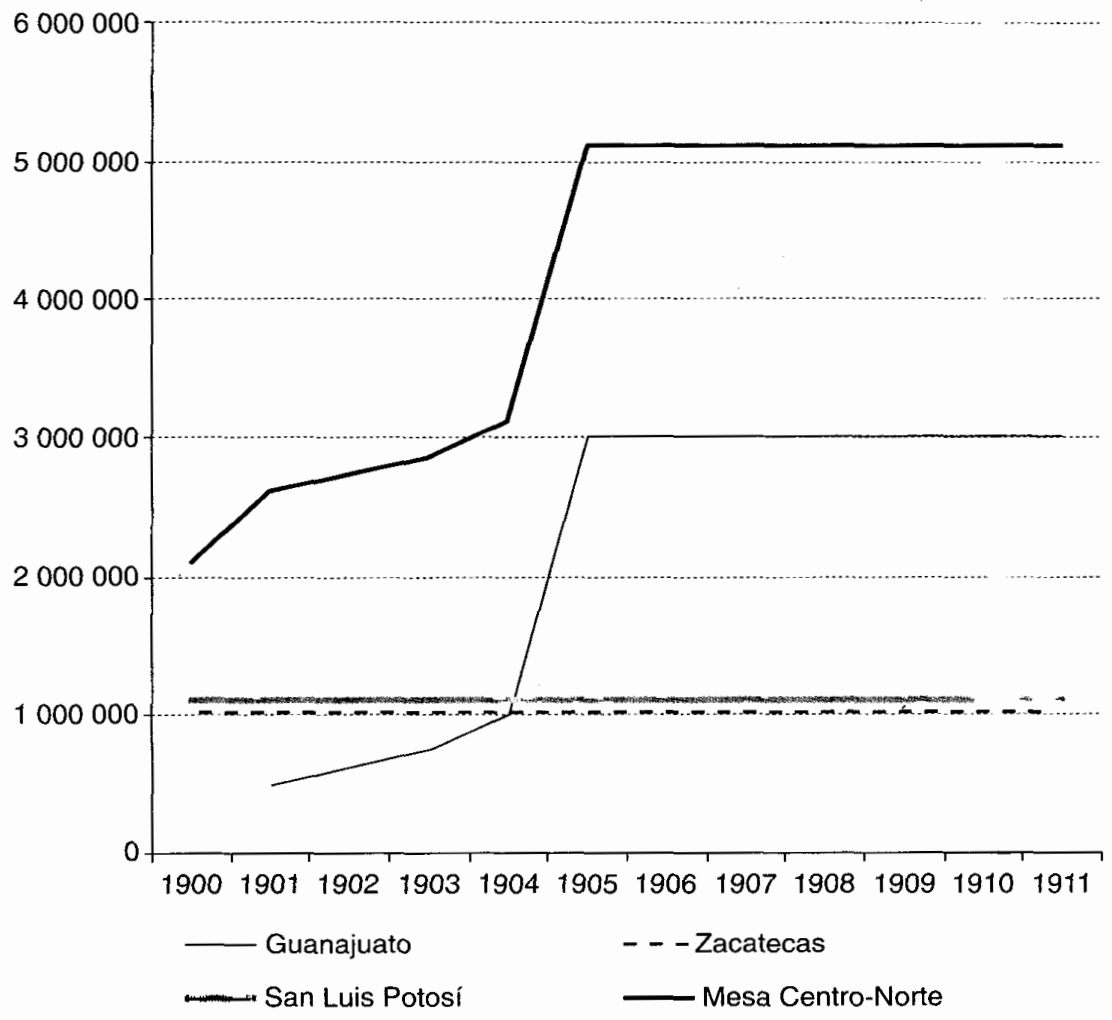

Fuente: Memoria, 1900-1911.

fueron afectadas, "aunque por fortuna solamente de manera indirecta, por los trastornos políticos que tuvieron lugar" en el país. ${ }^{46}$

${ }^{46}$ Memoria, 1.91 1, p. 227.
El manejo empresarial de dichas instituciones financieras tuvo detrás la precaución y las reservas hacia el riesgo. El desempeño del Banco de Zacatecas tuvo repercusiones originadas por la baja en el precio de la plata en el mercado internacional, que significó cierta paralización de 
Gráfica 2. Préstamos hipotecarios de la banca.

Mesa Centro-Norte de México, 1900-1911

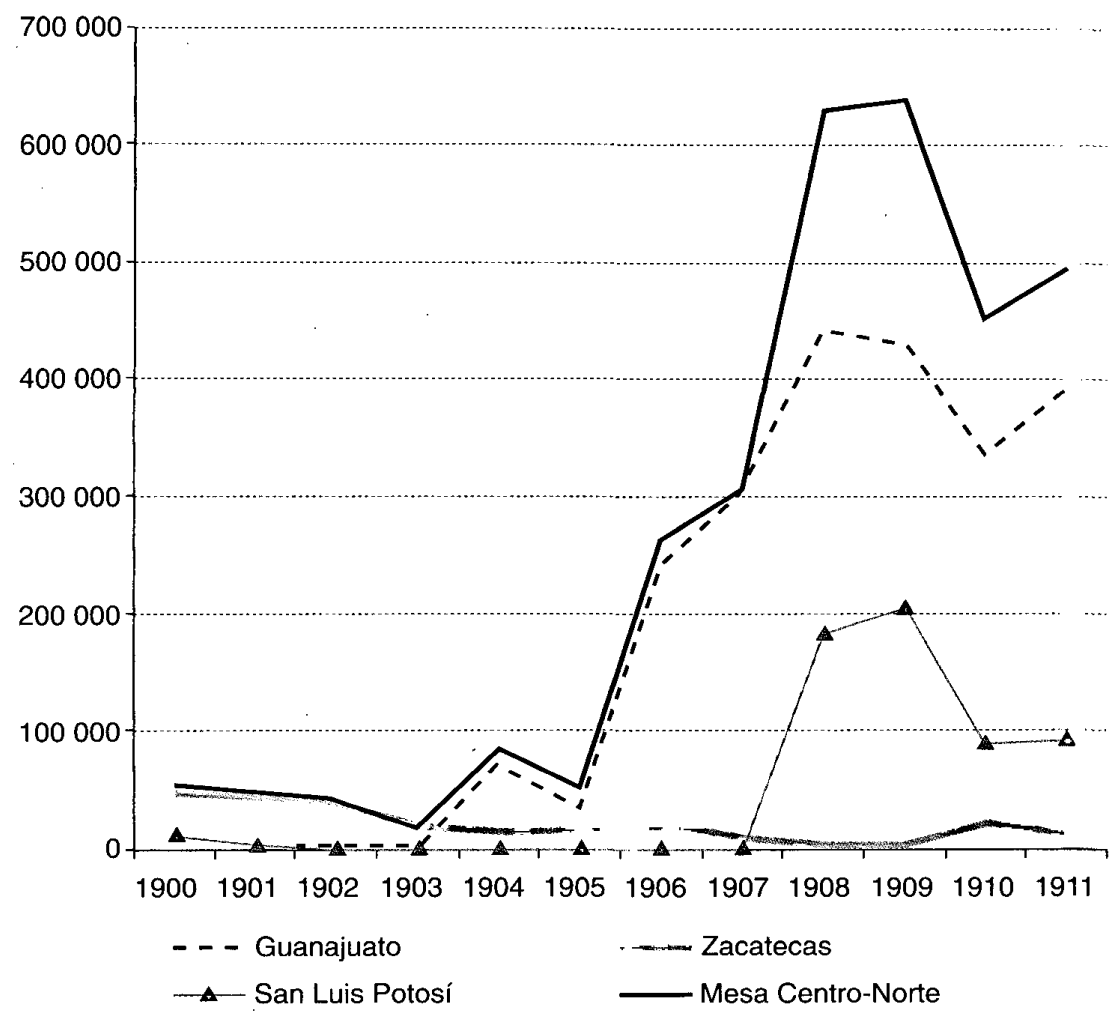

Fuente: Memoria, 1900-1911.

las actividades económicas, esencialmente en el sector minero. Frente a dicho fenómeno, el Banco decidió retirar del movimiento de los negocios una considerable suma que reservó en efectivo enteramente disponible, como precaución para cualquier emergencia. Los dividendos distri- buidos en 1909 fueron menores a los años anteriores. Es decir, las decisiones empresariales estuvieron sustentadas en una "política conservativa", prudente, que buscaba la "mayor solidez de la institución" ${ }^{47}$ Las

${ }^{47}$ Memoria, 1910, pp. 621-629. 
prácticas financieras también se reflejaron en la capacidad para otorgar préstamos hipotecarios. Hacia 1911 los directivos mostraban una actitud positiva, difundiendo que "la marcha del banco ha sido perfectamente regular". Lo que fue evidente es que la tendencia de los préstamos hipotecarios y la circulación de billetes reflejaron una curva decreciente.

Por su parte, el Banco de San Luis Potosí no manifestó capacidad para aumentar el capital social durante el periodo, pues se mantuvo en 1100000 pesos. No obstante, su estrategia fue diferente a la aplicada en otros lados. Se dirigió a ensanchar sus operaciones a través de la participación accionaria como una forma de distribuir los riesgos que consideraba se corrían al invertir en una sola entidad financiera. Como ya se explicó, inició con la inversión en el Banco de Guanajuato. A este hecho se suma que, en julio de 1902, accionistas del Banco de San Luis, como Gerardo Meade por sí y en representación de su hermano Eduardo, Guillermo R. Peterson como gerente de la casa $\mathrm{J} . \mathrm{H}$. Bahnsen y Compañía, Tomás Olavarria en representación de la sociedad Tomás Olavarria y Compañía S. C., Mariano Hernández Ceballos y Eugenio Labarthe, apoderado de Camilo Vallejo -de Aguascalientes-, formaron una sociedad para fundar el Banco de Aguascalientes. ${ }^{48}$ Los accionistas mayoritarios fueron el Banco de San Luis y los ya mencionados. Con esa transacción ampliaron la red de relaciones económicas que desde tiempo atrás venían expandiendo los empresarios potosinos. De esa forma

48 "Constitución del Banco de Aguascalientes", 2 de julio de 1902, en AHESLP, fondo Registro Público de la Propiedad y del Comercio, Jesús Hernández Soto, prot. 1902, insc. 2. articularon sus intereses en la banca en San Luis Potosí, Guanajuato y Aguascalientes, además de Zacatecas, aunque en menor medida.

El consejo de administración del Banco de San Luis también decidió conservar amplios fondos disponibles que aseguraran cualquier eventualidad. A mediados de la primera década del siglo $\mathrm{xx}$, sus depósitos habían aumentado, lo que le permitió años después incrementar su capacidad para los préstamos hipotecarios. Durante el ejercicio de 1909 los

negocios del banco mejoraron, a pesar de la crisis que prevaleció durante 1908 y que actualmente sus dos principales ramos de trabajo, como son los depósitos y la circulación de billetes, prosperaron durante el año de 1909.49

Hacia 1910 se presentaron ciertas anomalías por la acumulación de fondos mantenidos sin inversión en 1909 debido a la falta de demanda y empleo natural de los mismos. Se produjo una escasa movilización de fondos atribuidos en parte a la escasez de cosechas agrícolas, entre otros desequilibrios. ${ }^{50}$ Otro problema arrastrado por el banco era una cartera vencida a causa de préstamos por 60000 pesos realizados al gobierno en 1910 que no habían sido cubiertos aún en 1913. En su lugar se negoció un refrendo del adeudo más la aceptación de un interés de $8 \%$ anual. No obstante, el gobierno no daba señales de cumplimiento de las obligaciones crediticias. En ese tiempo se generaron fuertes interrupciones a la propia evolución de la banca en México por las fuerzas constitu-

\footnotetext{
${ }^{49}$ Menoria, 1909, p. 735.

${ }^{50}$ Memoria, 1910, pp. 667-686.
} 
cionalistas, entre 1913 y 1915 , que condujo a implementar cambios y ajustes. Fue hasta 1927 cuando el Congreso facultó al entonces gobernador, Abel Cano, para convenir el pago de 124800 pesos con el Banco de San Luis. El gobierno pagaría la deuda en diez mensualidades. Esta institución bancaria también tenía otros créditos a su favor desde varios años atrás, que contribuyeron a agravar el problema de la cartera vencida. ${ }^{51}$

Los primeros años del periodo revolucionario convulsionaron la evolución de la banca debido a múltiples factores sociales y económicos. La concesión del Banco de San Luis caducó el 4 de diciembre de 1915 a causa de que no tenía su circulación fiduciaria ajustada a lo prevenido por el artículo 16 de la Ley General de Instituciones de Crédito. ${ }^{52}$ Con ello, el desarrollo de la banca en la Mesa Centro-Norte y el entramado empresarial se enfrentó a nuevas condiciones que generaron la necesidad de una recomposición en las estrategias de actuación.

\section{CONCLUSIONES}

La presencia de prácticas informales de intermediación financiera y las formales creó redes empresariales en diversos sectores económicos y fortaleció las relaciones económicas en la Mesa Centro-Norte de México en las últimas décadas del siglo XIX.

El grupo que en décadas anteriores había controlado las actividades crediticias fue promotor de las entidades bancarias, que supone la ampliación de operaciones

${ }^{51}$ Montejano y Palacios, Cien, 1997.

52 Ankerson, Caudillo, 1994, pp. 134-137. y respaldo de sectores productivos. Dicho grupo mantuvo una estrecha relación intersectorial, creando un amplio entramado de intereses por medio de la participación accionaria y la financiación de proyectos.

Las primeras instituciones financieras se establecieron en centros agrícolas, mineros e industriales de importancia en el plano nacional, como Chihuahua, Zacatecas, San Luis Potosí y Guanajuato. En este sentido, la concentración geográfica hizo que las redes financieras fueran importantes.

Las formas de financiamiento dejan sentadas las bases para dar respuesta a la proliferación de pequeños, medianos y grandes proyectos empresariales. Respaldaron empresas cuya cartera accionaria inclúa sujetos y figuras de reconocida trayectoria económica y prestigio social, lo que fomentó el establecimiento de importantes negocios y la renovación tecnológica. Las contradicciones del sistema tampoco se pueden dejar de lado, ya que el abundamiento en la formación de empresas con capitales liliputienses también está vinculado estrechamente con el sistema crediticio que no apoyó proyectos en los cuales existía un mayor riesgo por la poca experiencia en las actividades, la escasa capacidad económica y el atraso tecnológico.

Existieron notables diferencias en la trayectoria de las instituciones bancarias en la Mesa. Es notable la de Guanajuato por sus recurrentes aumentos de capital social y su capacidad crediticia; asimismo, es evidente la conjunción de empresarios de diversas partes, primordialmente de San Luis Potosí.

La red de empresarios potosinos tuvo un desempeño ejemplar por su diversificación y la consolidación de vínculos econó- 
micos. Además del asentamiento de importantes casas comerciales con funciones financieras, y de la gestación y desarrollo del Banco de San Luis, intervino de manera directa en el establecimiento de la banca en Guanajuato y Aguascalientes y participó en la de Zacatecas, lo que muestra una mentalidad cuyo cimiento estuvo en la extensión de relaciones más allá de los límites estatales que posibilitó una mayor configuración de la Mesa Centro-Norte. Demuestra un entramado social y económico sobre los poseedores del capital a lo largo del tiempo, en un espacio definido, y el tipo de transacciones extendidas.

\section{ARCHIVOS}

AGEG Archivo General del Estado de Guanajuato.

AHEsLP Archivo Histórico del Estado de San Luis Potosí.

AHEZ Archivo Histórico del Estado de Zacatecas.

AHG Atchivo Histórico de Guanajuato (Universidad de Guanajuato).

\section{Hemerografía}

-Diario Oficial de la Federación, México, 1897.

-Periódico Oficial del Estado de San Luis Potosí, 1882, 1897.

\section{BIBLIOGRAFÍA}

-Ankerson, Dudley, El caudillo agrarista: Saturnino Cedillo y la revolución mexicana en San Luis Potosí, INEHRM, México, 1994.

- Banco de San Luis Potosí (Sociedad Anónima) establecido con arreglo a la ley general de instituciones de crédito de 19 de marzo de 1897 y en virtud de la concesión respectiva otorgada por el gobierno de la Unión. Capital: un millón cien mil pesos. Asamblea general ordinaria, 2 de marzo de 1899, Tipografía y Encuadernación El Libro Mayor, San Luis Potosí, 1901.

- Banco de Zacatecas. Capital: seiscientos mil pesos. Séptima asamblea anual general ordinaria de 10 de febrero de 1898. Informes del consejo de administración y del comisario. Resoluciones de la asamblea general, Imprenta y Litografía de Nazario Espinosa, Zacatecas, 1898.

- Banco de Zacatecas. Decreto de concesión, franquicias concedidas por el gobierno de Zacatecas. Escritura de sociedad y estatutos, Imprenta de Francisco Díaz de León, México, 1891.

-Banco de Zacatecas. Décima asamblea anual. Informes del consejo de administración y del comisario. Resoluciones de la asamblea general, Papelería y Talleres de N. Espinosa, Zacatecas, 1901.

-Bátiz, José Antonio, "Trayectoria de la banca en México hasta 1910" en Leonor Ludlow y Carlos Marichal (comps.), Banca y poder en México, 1800-1925, Grijalbo, México, 1986, pp. $267-$ 297.

-Cabrera Ipiña, Octaviano y Matilde Cabrera Ipiña, San Francisco Javier de La Parada, Editorial Universitaria Potosina, San Luis Potosí, 1978.

-Cerutti, Mario, "La expansión del crédito prebancario: diferencias regionales" en Leonor Ludlow y Jorge Silva Riquer (comps.), Los negocios y las ganancias en México de la colonia al México moderno, Instituto Mora/UNAM, México, 1993, pp. 298-312.

, Propietarios, empresarios y empresa en el norte de México, Siglo.XXI, México, 2000. y Carlos Marichal, "Estudio introductorio" en Mario Cerutti y Carlos Marichal (coords.), La banca regional en México (18701930), FCE/COLMEX, México, 2003, pp. 9-46.

- Código de Comercio de los Estados Unidos Mexicanos, Tipografía de Gonzalo A. Esteva, México, 1884. 
-Gámez, Moisés, "Propiedad y empresa minera en la Mesa Centro-Norte de México. Guanajuato, San Luis Potosí y Zacatecas, 1880-1910", tesis de doctorado, Universidad Autónoma de Barcelona, Barcelona, 2004.

-Kuntz Ficker, Sandra y Luis Jáuregui, "Entre el pasado y el presente: $1867-1940$ " en Jesús Flores Olague et al., Historia mínima de Zacatecas: la fragua de una leyenda, Limusa/Grupo Noriega Editores, México, 1995, pp. 133-189.

- Ley General de Instituciones de Crédito, Secretaría de Estado y del Despacho de Hacienda y Crédito Público/Tipografía de la Oficina Impresora del Timbre, México, 1897.

-Ludlow, Leonor, "La primera etapa de formación bancaria (1864-1897)" en Leonor Ludlow y Jorge Silva Riquer (comps.), Los negocios y las ganancias en México de la colonia al México moderno, Instituto Mora/UNAM, México, 1993, pp. 330-359.

"La construcción del Banco Nacional de México" en Leonor Ludlow y Carlos Marichal (comps.), Banca y poder en México, 1800 1925, Grijalbo, México, 1986, pp. 299-345.
-Marichal, Carlos, "El nacimiento de la banca mexicana en el contexto latinoamericano: problemas de periodización" en Leonor Ludlow y Carlos Marichal (comps.), Banca y poder en México, 1800-1925, Grijalbo, México, 1986, pp. 231265.

-Matamala Vivanco, Juan, "La Casa de Moneda de Zacatecas (1810-1905)", comunicación en $V$ Reunión de Historiadores de la Minería Latinoamericana, El Colegio de San Luis, San Luis Potosí, 1997.

- Memoria de las instituciones de crédito, Tipografía de la Oficina Impresora del Timbre, México, 1900-1911.

-Montejano y Aguiñaga, Rafael y Ana María de Palacios, Cien años de la banca potosina, Artes Gráficas del Centro, San Luis Potosí, 1997.

-Riguzzi, Paolo, "Los pobres por pobres, los ticos por ignorancia. El mercado financiero en México, 1880-1925: las razones de una ausencia" en Marcelo Carmagnani, Alicia Hernández Chávez y Ruggiero Romano (coords.), Para una bistoria de América II. Los nudos (1), FCE/COLMEX, México, 1999, pp. 344-378. 